\title{
Richieri Costa-da Silva syndrome
}

INSERM

\section{Source}

INSERM. (1999). Orphanet: an online rare disease and orphan drug data base. Richieri Costa-da Silva syndrome. ORPHA:3101

Richieri Costa-da Silva syndrome is a rare, genetic, myotonic syndrome characterized by childhood onset of progressive and severe myotonia (with generalized muscular hypertophy and progressive impairment of gait), short stature, skeletal abnormalities (including pectus carinatum, short, wedge-shaped thoracolumbar vertebrae, kyphoscoliosis, genu valgum, irregular femoral epiphyses), and mild to moderate intellectual deficiency. No facial dysmorphism nor joint limitation is associated. There have been no further descriptions in the literature since 1984. 